\title{
Beta cells under attack: toward a better understanding of type 1 diabetes immunopathology
}

\author{
Ken T. Coppieters • Bart O. Roep • \\ Matthias G. von Herrath
}

Received: 16 September 2010 /Accepted: 7 December 2010 /Published online: 18 December 2010

(C) Springer-Verlag 2010

The fact that type 1 diabetes (T1D) is caused by an aberrant autoimmune response against beta cells has been known for almost half a century. Today, several decades after the first report on immune cells invading the pancreatic islets from recently diagnosed children [1], our knowledge on the disease's immunopathology has dramatically improved. Yet, despite extensive research, diagnosed individuals are still condemned to a lifetime of meticulous glucose monitoring and insulin replacement therapy. A more detailed understanding of disease mechanisms is required in order to efficiently curb islet autoimmunity and ultimately design appropriate cures. Islet transplantation may serve as an example as the majority of recipients develop recurrent islet autoimmunity, indicating that simply replenishing beta cell mass is not a feasible option unless the underlying immune response is tackled [2, 3]. The aim of this special issue is to review some of the immunopathologic features that make T1D such a complex autoimmune condition. This opening chapter will provide an introduction to the topics covered by some leading specialists.

\section{Histological studies}

The pancreas is a very difficult organ to study, for obvious reasons. It is a diffuse organ roughly located

K. T. Coppieters $\cdot$ M. G. von Herrath $(\bowtie)$

La Jolla Institute for Allergy and Immunology,

9420 Athena Circle,

La Jolla, CA 92037, USA

e-mail: matthias@liai.org

B. O. Roep

Department of Immunohematology \& Blood Transfusion,

Leiden University Medical Centre,

Leiden, The Netherlands between spleen and stomach, deep inside the abdominal cavity. The islets of Langerhans are found scattered throughout the exocrine portion of the pancreas, with the latter producing large amounts of digestive enzymes. Obtaining biopsy samples under these conditions is considered extremely risky and is generally avoided for research purposes. There have been some Japanese studies showing that the procedure can be performed safely, but the approach yields only very small samples $[4,5]$, which brings us to another caveat in studying T1D, i.e., its patchy, lobular distribution, a hallmark that's been acknowledged since the early studies by the late Willy Gepts in the 1960s and decades later by Foulis and coworkers [6].

Our methodological options in studying immune responses at the islet site are thus extremely limited. Histological studies have traditionally applied immunohistochemical or immunofluorescent detection procedures and valuable insights were obtained particularly with samples from recently diagnosed individuals. Important contributions were made by Foulis and coworkers in the 1980s, all of which were based on a patient cohort consisting of recently diagnosed children [6]. Sarah Richardson has recently revisited the immunopathology of the same samples using modern antibodies and she will elaborate on this analysis in a later chapter [7]. Based on the early detection of autoantibodies in prediabetic individuals, we can reasonably assume that clinical diabetes onset represents the outcome of several years of ongoing islet autoimmunity. Results by In 't Veld and colleagues were surprising at first sight, finding insulitis in only two out of 62 nondiabetic autoantibody-positive organ donors, in less than $10 \%$ of the islets [8]. These two patients with insulitis, however, displayed positivity for three autoantibodies which is strongly predictive of T1D development. The lack of insulitis in the other cases 
may be indicative of the subtle nature of the diabetogenic process, or may reflect a relapsing-remitting course [9]. It is conceivable that disease mechanisms and progression patterns will be hetergeneous among different type 1 diabetic patients.

The advent of coordinated procurement programs such as the network for Pancreatic Organs Donors (nPOD) are anticipated to challenge many of the conclusions drawn from old samples. The first results originating from nPOD samples were reported by Gianani and coworkers and revealed some intriguing characteristics of longstanding T1D, including upregulation of stress markers such as human leukocyte antigen (HLA) class I and survivin [10]. A particularly hopeful message comes from pancreata obtained from "Joslin Medalists", individuals who have a documented 50-year history of T1D. In all nine cadaveric cases that were examined, insulin-producing beta cells were demonstrated and approximately $70 \%$ of living medalists exhibited remaining C-peptide levels [11]. It can be concluded that beta cells may possess stronger survival or recovery mechanisms than previously assumed. Just like most other tissues, beta cells do have regenerative capacity and respond to inflammatory conditions with vigorous proliferation $[12,13]$.

Some outstanding questions pertaining to T1D immunopathology

-A better understanding of early events in islets from prediabetic, atrisk individuals

-More systematic histology data in recent-onset pancreata: CD4/CD8 $\mathrm{T}$ cell subsets, B cell/macrophage involvement, beta cell proliferation, and apoptosis rate

-What are the mechanisms of beta cell death in humans?

-How do we noninvasively quantify beta cell mass?

-What do insulitic T cells see?

-Are T1D-associated T cell specificities found in the blood functionally relevant?

-Where do Treg primarily exert their immunoregulatory action?

-The role of viral infections: when can which strain(s) be detected and where?

-Immunological characterization of the "honeymoon" phase as an ideal therapeutic window

A major technical hurdle has been the dynamic, noninvasive follow-up of beta cell mass fluctuations at various stages of the disease and during experimental treatment through imaging. PET-based applications were successfully applied in animal models, but are still not available as a standardized procedure in the clinic [14]. At present, C-peptide measurement remains the standard, but its accuracy as a surrogate for true beta cell mass is doubtful. The transient honeymoon phase, a recovery period experienced by most diagnosed individuals, illustrates how C-peptide readouts may be misleading. This temporary window of normalization is thought to be the consequence of regained insulin production by nonfunctional beta cells rather than short-term expansion of total beta cell mass (see below).

\section{Diabetogenic $T$ cells}

Whereas a pivotal role has been ascribed to other immune cell subsets (discussed in a subsequent chapter by Franscesco Dotta), T cells remain prime suspects with regard to the infliction of beta cell damage. Notable progress has been made in the discovery of diseaseassociated $\mathrm{T}$ cell epitopes, and we now have a rapidly developing idea of what these $T$ cells are "seeing". The notion that many of the targeted molecules are not specific to the beta cell (e.g., glutamic acid decarboxylase) suggests stringently localized presentation and regulatory mechanisms or, alternatively, the occurrence of intermolecular epitope spreading. In the non-obese diabetic (NOD) mouse, it was shown that up to $60 \%$ of CD8 $\mathrm{T}$ cells obtained from diabetic islets recognize either insulin, islet-specific glucose-6-phosphatase catalytic subunit-related protein, or dystrophia myotonica kinase [15]. Such data favor the idea that we have identified the majority of key $\mathrm{T}$ cell antigenic determinants, at least in NOD mice. However, these answers immediately bring up important new questions with regard to the functional relevance of these specificities in driving the disease. George Eisenbarth and colleagues have made a strong case for insulin as the initiating antigen in the NOD mouse [16] which would imply a secondary role for all other diabetogenic $\mathrm{T}$ cells in subsequent stages. The cardinal limitation of the available dataset is undoubtedly the fact that tissue sampling from T1D subjects is currently largely restricted to peripheral blood. As a consequence, our hypotheses are usually built on the premise that the T cell population found in the blood at least to some extent mirrors the one that infiltrates the islets. There is evidence from the NOD mouse showing that there is indeed a considerable degree of correspondence [17, 18], but profound fluctuations in time are noticeable and confirmation in humans is still lacking. Likewise, autoantibodies 
remain a very superficial parameter in characterizing events at the islet site. Whereas their combined detection profile enables us to predict disease development with high specificity and sensitivity, autoantibodies should still be regarded as "smoke" originating from distant "fire", i. e., insulitis in the pancreas. Mark Atkinson's contribution here is appropriately titled "The pancreas in T1D" and focuses on the events in the target organ.

Provided that the appropriate technical approach is employed, tracking $\mathrm{T}$ cell responses in peripheral blood can be a reliable T1D-associated parameter [19]. The recent development of combinatorial major histocompatibility complex (MHC) class I multimers to simultaneously detect multiple islet-specific CD8 $\mathrm{T}$ cells in small sample volumes should add to the established array of protocols [20]. Using conventional HLA class I tetramers, Velthuis and colleagues were able to detect isletreactive specificities in an inflamed pancreas allograft of a T1D patient, be it in much higher frequencies than in the blood [21]. Such evidence indicates that any $\mathrm{T}$ cell measurement in the blood, both in terms of frequencies and functionality, likely represents only the tip of the iceberg. Nevertheless, such analysis may suffice for the continuous monitoring of disease status, efficacy of beta cell replacement, or follow-up during immunomodulatory therapies.

\section{Regulatory $T$ cells and how to therapeutically exploit them}

In healthy individuals, potentially diabetogenic $\mathrm{T}$ cells are thought to be kept in check by the immunoregulatory action of regulatory $\mathrm{T}$ cells (Treg). Recent experimental immune interventions aimed at expanding this cellular compartment have shown promise in mouse models and humans, but few data exist on their role during the natural course of T1D development. There appears to be no consistent difference in the frequency of CD4+CD25+ $\mathrm{T}$ cells in T1D patients as compared to control subjects $[22,23]$, and Treg were a very rare finding in the pancreas sections studied histologically by Willcox et al. [7], as far as phenotypic studies can tell, given the lack of distinct Treg markers in humans. However, naturally occurring Tregs isolated from T1D patients do show inferior suppression, suggesting that future research should characterize these cells from a functional rather than quantitative perspective. More recent work claims that effector $\mathrm{T}$ cells of type 1 diabetic patients seem resistant to immune regulation by nTregs, adding to the immune imbalance in favor of autoimmune beta cell destruction [24]. Whether differences between islet antigen-specific Tregs [25] can distinguish healthy and type 1 diabetic patients remains to be determined.

A therapeutic option that was recently explored consists of repeated low-dose IL-2 administrations as a means to specifically expand the pancreatic Treg population [26]. Previous work had identified the relative IL-2 deficiency in the NOD mouse pancreas as a cause for intra-islet Treg cell dysfunction [27]. The same group also demonstrated that Treg exhibit extraordinary flexibility in their transcriptional profile and functional phenotype and can convert into effector T cells under conditions of inflammation [28]. When it turns out that immune therapies such as IL-2 predominantly act by expanding or recruiting local Treg to the islets, it will be essential to ascertain that functional stability is sufficient so as to avoid later conversion should autoimmunity recur.

In conclusion, most of what we know about Treg and, in particular, their numbers and functionality in the pancreas is derived from animal models at this point and largely limited to naturally occurring Tregs rather than antigen-specific suppressor T cells. An ideal, albeit complicated approach to assess the presence, phenotypes, and functionality of the islet-infiltrating population would be to sample pancreas tissue from prediabetic or recent-onset cadaveric donors followed by flow cytometric analysis. In parallel, immunohistochemistry studies for Foxp3 as performed by Willcox et al. should be expanded to complete the picture.

Immunopathogenesis of type 1 diabetes-This cartoon provides an overview of the disease mechanisms that are thought to be involved at various stages of T1D development. Whereas the etiology is still unresolved, it is thought that an environmental trigger, such as viral infection, is required for susceptible individuals to develop disease. The beta cells, in response, produce inflammatory mediators such as interferon-alpha and upregulate their surface expression of MHC class I. Under such conditions of stress, beta cell antigens are released and taken up by antigen-presenting cells (APCs). The APCs migrate to the pancreatic draining lymph nodes and cross-present beta cell autoantigens to both Th1 cells and regulatory $\mathrm{T}$ cells (Treg), with a critical role for TNF-alpha in generation of Treg. In normal individuals, Treg inhibit the action of Th1 cells via cytokines such as IL-10. In susceptible individuals, however, a detrimental Th1 response and interferon (IFN)-gamma production is initiated, leading to $\mathrm{B}$ cell activation and autoantibody production. Together with direct recognition and killing of beta cells by cytotoxic $\mathrm{T}$ lymphocytes (CTL), these effector mechanisms ultimately lead to beta cell death and insulin insufficiency. 


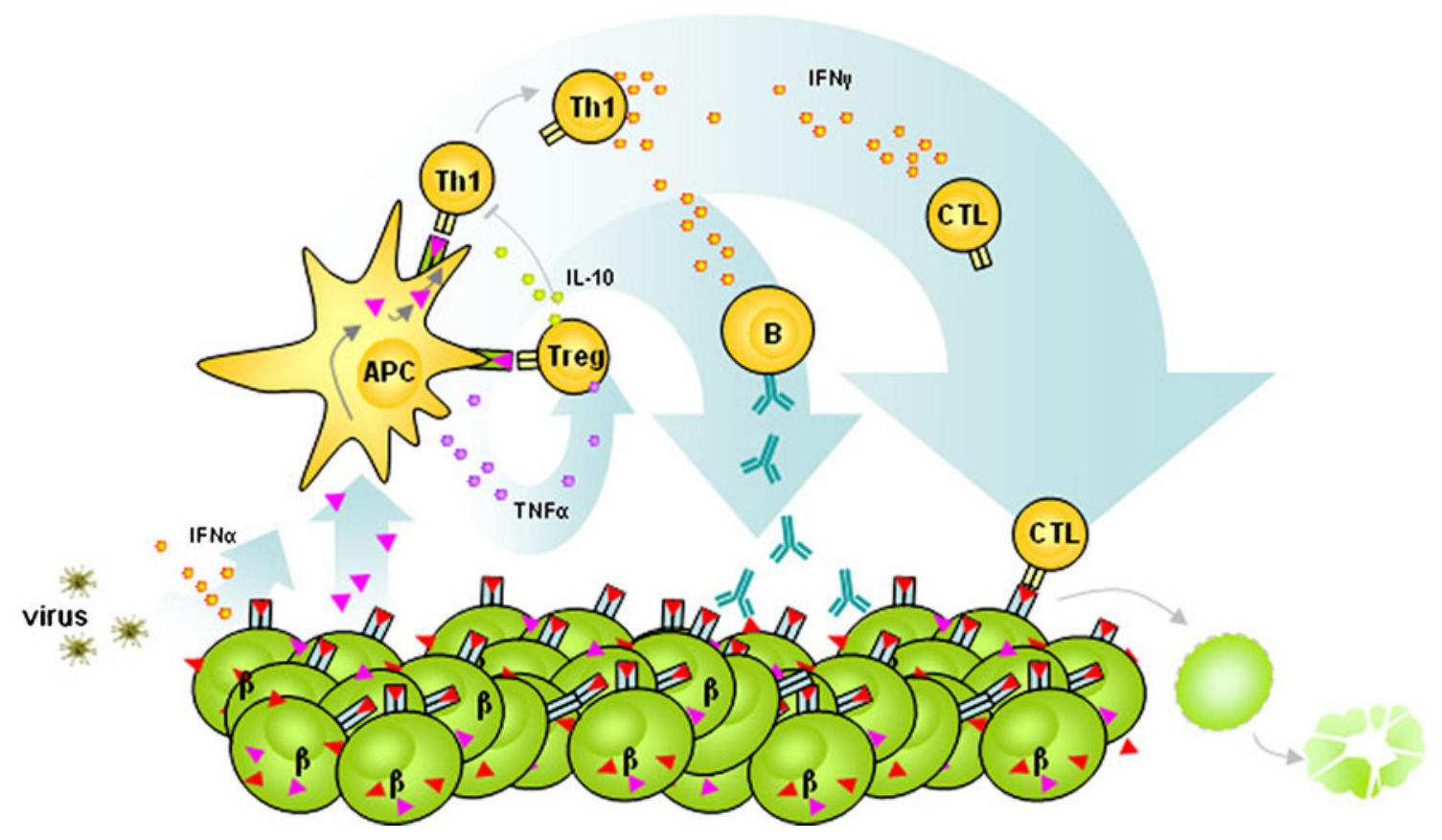

\section{The honeymoon phase - therapeutic window par excellence}

A sizeable impediment to efficient treatment is that at the time of clinical T1D manifestation, patients have lost somewhere between $60 \%$ and $90 \%$ of their functional beta cell mass. Studies in the NOD mouse, however, have found a substantial pool of nonfunctional, insulin-depleted beta cells at the onset of hyperglycemia [12]. This notion underscores our current limitation to study beta function, which may be a rather poor surrogate of actual beta cell mass. Depending on the quantity of dysfunctional yet live beta cells, one could therapeutically target these degranulatedd beta cells to regain insulin secretion, which may constitute a more achievable short-term goal as compared to beta cell regeneration. Indeed, however controversial it may be, the nonmyeloablative intervention therapy assessed in Brazil leading to extended insulin independency in a large proportion of recent-onset type 1 diabetic patients suggests that aggressive immune intervention combined with beta cell recovery may offer lasting remission in clinical type 1 diabetes [29]. Another interesting window of opportunity in this respect is the transient remission of some degree after initiation of insulin treatment in up to $60 \%$ of T1D patients, a period termed the "honeymoon phase". During this phase, which often lasts 3-6 months but may continue for 2 years, insulin doses can be greatly reduced or even withdrawn completely. The mechanisms governing improved beta cell function are poorly understood, but it is thought that the constant hyperglycemic stimulus exhausts beta cells. Initiation of insulin treatment relieves this stress factor which in turn allows dysfunctional beta cells to temporarily replenish their insulin content. Our group has studied the remission phase from an immunological perspective in a small cohort of patients, focusing on antigen-specific cytokine responses from T cells in the peripheral blood. Surprisingly, we found lower FoxP3 levels in CD4+CD25+ Tregs and lower numbers of IL-10-producing cells in remission patients versus new-onset cases [30]. In a limited cross-sectional prospective study, we found that higher FoxP3 expression at diagnosis predicted worse glycemic control while higher mean numbers of IL-10 cells were associated with better future glucose control. Another follow-up study in a large cohort of pediatric new-onset type 1 diabetes patients showed evidence for associations of adiponectin, interleukin (IL)-1 ra, inducible protein 10, IL-6, and number of islet autoantibodies with progression patterns of type 1 diabetes the first year after diagnosis [31]. These data suggest that there may be an immunological component underlying the honeymoon phase and serve as an argument for curbing autoimmunity by antigen-specific immunomodulation soon after diagnosis. Yet, it also underscores the current lack of knowledge of disease progression after diagnosis and the lack of biomarkers thereof [32].

\section{The environment — a viral cause for T1D?}

While we are gaining ground in discovering the islet antigens that are recognized and characterizing the $\mathrm{T}$ cells that recognize them, much less is known about what triggers their activation. Genetic susceptibility is certainly critical in most 
scenarios, with a virtually endless list of putative susceptibility genes and combinations thereof within the immune activation pathway. The majority of genetic predisposition lies in the MHC region, but the list of other predisposing polymorphisms reads like a "who's who" in the immune cell activation field. The emerging thought is that the need for an environmental T1D trigger depends on the level of genetic predisposition, both of which interact at a continuous threshold. For instance, patients with mutations in the Treg master transcriptional regulator Foxp3 are at the far end of the spectrum and will develop T1D regardless of environmental impact. At the opposite side, one could envision the recently characterized Japanese subset of autoantibody-negative, "fulminant diabetes", where most islets seem to be infected by enterovirus [33]. Most T1D cases are situated in between both extremes and would benefit from the detailed characterization of infectious agents that can potentially elicit islet autoimmunity.

Among the many viruses that have been implicated in T1D etiology, enteroviruses and in particular coxsackieviruses have received the majority of attention. Righteously so, since numerous studies have found an increased frequency of enteroviral infection around T1D onset and animal data clearly indicate that these viruses can both prevent or accelerate disease [34]. A substantial body of evidence has come from the Finnish population, which harbors the world's highest number of T1D patients. Finnish investigator Heikki Hyoty will discuss arguments favoring the involvement of virus and will speculate on how this may interfere with a T1D-susceptible immune system. The T1D incidence in Finland has been documented as the world's highest, but was recently found to be increasing even more rapidly than before [35]. Since genetic constitution of the population cannot be responsible for any increases in such a narrow time span, these data suggest that something in the environment is gradually changing. In combination with the long-known seasonal onset pattern of T1D, no complicated experimental setup is required to suspect that infectious agents may play a role [36]. A wide variety of possible etiologic mechanisms have been postulated, one of which is that enteroviruses may be able to chronically infect beta cells and directly provoke upregulation of MHC class I and interferon-alpha followed by CTL-mediated killing [37]. Direct evidence for this hypothesis was provided recently by immunohistochemical selective detection of enteroviral protein in beta cells in islets from a small series of recent-onset T1D patients [38], and corroborated by a much larger series, where 44 out of 72 recent-onset patients (the same set as described by Alan Foulis in the 1980s) versus three out of 50 controls [39]. The finding that the same applied for ten out of 25 type 2 diabetics suggests that some phenomena may be shared between T1D and T2D.
Without the proper genetic constitution, however, viruses are unable to mediate progression to islet autoimmunity. The recent discovery of T1D-associated polymorphisms in the interferon-induced helicase 1 (IFIH1) region may highlight the link between genetic constitution and viral infections [40]. IFIH1 codes for an IFN-induced helicase that contributes to recognition of dsRNA from picornaviruses, and thus, serves as a cytoplasmic sensor for viral infection. Now, let it be a coincidence that coxsackieviruses belong to the picornavirus family. A genetic defect in IFIH1 could potentially interfere with proper detection and clearance of viral infections and leads to the production of Type I interferons and an aberrant diabetogenic immune response. The identification of rare T1D-protective IFIH1 variants, which reduce the protein's functionality, is in line with this hypothesis [41].

What do we need to corroborate our data on the involvement of enteroviruses and how do we best intervene? With regard to the detection of virus in blood, stool, or postmortem pancreas tissue, a systematic approach on large sample numbers before or around onset should be the norm. Exciting new data from the DAISY study suggest that progression from islet autoimmunity to T1D may increase after an enterovirus infection [42]. Furthermore, almost all sequenced samples were categorized in the enterovirus genogroup II, to which the coxsackie B viruses belong. As support for a causal role is mounting, why don't we start with the immunization of at-risk children? The main limitation at present is that the Enterovirus genus of the Picornaviridae family consists of five virus species. These virus species in turn contain many different strains and serologically distinct viruses [43]. Any one or a combination of these viruses could be the virus detected in pancreatic tissue of diabetes type 1 patients by the anti-VP1 antibody that is commonly used. Finnish groups are currently sorting out which are the most prevalent strains in T1D patients in order to clarify against which serotypes should be immunized [44]. Finally, caution is warranted as, depending on the genetic background of the host, there is a possibility that viruses may also confer protection, an observation that is now becoming fairly established in mouse models [45].

\section{Mouse models-imperfect yet indispensible tools}

The development of animal models, and in particular the NOD mouse, has contributed in providing tools for in-depth mechanistic studies and preclinical assessment of potential therapeutics. Opponents traditionally cite the many discrepancies with human disease and the high failure rate in translating therapies from mouse to man. A few years ago, Shoda and coworkers performed a comprehensive literature search and found that over 200 agents are capable of preventing disease in the NOD mouse [46]. For instance, 
repeated injections of saline were reported to do the job under certain conditions, obviously a therapeutic strategy unlikely to ever reach the clinic [47]. Whereas such limitations associated with animal research need to be taken into account, one cannot deny the crucial insights it has and continues to generate. One example is the notion that coxsackievirus infections can profoundly influence the disease course in the NOD mouse, which is exactly the kind of data that are rather difficult to obtain in humans [48]. David Serreze's contribution will zoom in on the important role for animal models in delineating disease mechanisms and future directions in improving translational research. Dr. Serreze has recently pioneered the design of humanized NOD mice carrying human class I constructs. These animals thus present epitopes restricted to human HLA molecules and develop a repertoire of diabetogenic, islet-infiltrating CD8 $\mathrm{T}$ cells that shows remarkable correspondence with specificities found in human peripheral blood [20,49]. This kind of approach may aid in bridging the gap between mice and men and suggests that animal models will continue to play a crucial role in T1D research for many years to come. The challenge for the diabetes research community will be to distinguish between the rights and wrongs of preclinical models [50].

\section{Conclusion}

While we proceed with the design of intervention strategies for T1D, we should continue to reconsider and challenge our opinion on the disease's immunopathological features. Many histological studies performed on pancreata from prediabetic or recent-onset individuals either study decades-old samples or are limited by small numbers. A more comprehensive procurement effort such as adopted by nPOD is required to answer questions about the cellular constitution of the insulitic infiltrate or the involvement of viruses. Meanwhile, the only routinely available source of information remains the peripheral blood, and $\mathrm{T}$ cell assays are rapidly evolving to become reliable surrogates in characterizing disease activity. Exploring the relevance of the $\mathrm{T}$ cells originating from this peripheral $\mathrm{T}$ cell pool as compared to the actual diabetogenic effectors in the islets will aid in exploiting them as biomarkers.

\section{References}

1. Gepts W (1965) Pathologic anatomy of the pancreas in juvenile diabetes mellitus. Diabetes 14(10):619-633

2. Hilbrands R, Huurman VA, Gillard P, Velthuis JH, De Waele M, Mathieu C et al (2009) Differences in baseline lymphocyte counts and autoreactivity are associated with differences in outcome of islet cell transplantation in type 1 diabetic patients. Diabetes 58 (10):2267-2276, PMCID: 2750206

3. Roep BO, Stobbe I, Duinkerken G, van Rood JJ, Lernmark A, Keymeulen B et al (1999) Auto- and alloimmune reactivity to human islet allografts transplanted into type 1 diabetic patients. Diabetes 48(3):484-490

4. Hanafusa T, Miyazaki A, Miyagawa J, Tamura S, Inada M, Yamada $\mathrm{K}$ et al (1990) Examination of islets in the pancreas biopsy specimens from newly diagnosed type 1 (insulin-dependent) diabetic patients. Diabetologia 33(2):105-111

5. Itoh N, Hanafusa $\mathrm{T}$, Miyazaki A, Miyagawa J, Yamagata $\mathrm{K}$, Yamamoto $\mathrm{K}$ et al (1993) Mononuclear cell infiltration and its relation to the expression of major histocompatibility complex antigens and adhesion molecules in pancreas biopsy specimens from newly diagnosed insulin-dependent diabetes mellitus patients. J Clin Invest 92(5):2313-2322, PMCID: 288412

6. Foulis AK, Liddle CN, Farquharson MA, Richmond JA, Weir RS (1986) The histopathology of the pancreas in type 1 (insulindependent) diabetes mellitus: a 25 -year review of deaths in patients under 20 years of age in the United Kingdom. Diabetologia 29(5):267-274

7. Willcox A, Richardson SJ, Bone AJ, Foulis AK, Morgan NG (2009) Analysis of islet inflammation in human type 1 diabetes. Clin Exp Immunol 155(2):173-181, PMCID: 2675247

8. In't Veld P, Lievens D, De Grijse J, Ling Z, Van der Auwera B, Pipeleers-Marichal M et al (2007) Screening for insulitis in adult autoantibody-positive organ donors. Diabetes 56(9):2400-2404

9. von Herrath M, Sanda S, Herold K (2007) Type 1 diabetes as a relapsing-remitting disease? Nat Rev Immunol 7(12):988-994

10. Gianani R, Campbell-Thompson M, Sarkar SA, Wasserfall C, Pugliese A, Solis JM et al (2010) Dimorphic histopathology of long-standing childhood-onset diabetes. Diabetologia 53(4):690 698

11. Keenan HA, Sun JK, Levine J, Doria A, Aiello LP, Eisenbarth G et al (2010) Residual insulin production and pancreatic beta cell turnover after 50 years of diabetes: Joslin Medalist Study. Diabetes 59(11):2846-2853

12. Sherry NA, Kushner JA, Glandt M, Kitamura T, Brillantes AM, Herold KC (2006) Effects of autoimmunity and immune therapy on beta-cell turnover in type 1 diabetes. Diabetes 55(12):32383245

13. Willcox A, Richardson SJ, Bone AJ, Foulis AK, Morgan NG (2010) Evidence of increased islet cell proliferation in patients with recent-onset type 1 diabetes. Diabetologia 53(9):2020-2028

14. Souza F, Simpson N, Raffo A, Saxena C, Maffei A, Hardy M et al (2006) Longitudinal noninvasive PET-based beta cell mass estimates in a spontaneous diabetes rat model. J Clin Invest 116 (6):1506-1513, PMCID: 1462946

15. Lieberman SM, Takaki T, Han B, Santamaria P, Serreze DV, DiLorenzo TP (2004) Individual nonobese diabetic mice exhibit unique patterns of $\mathrm{CD} 8+\mathrm{T}$ cell reactivity to three islet antigens, including the newly identified widely expressed dystrophia myotonica kinase. J Immunol 173(11):6727-6734

16. Nakayama M, Abiru N, Moriyama H, Babaya N, Liu E, Miao D et al (2005) Prime role for an insulin epitope in the development of type 1 diabetes in NOD mice. Nature 435(7039):220-223, PMCID: 1364531

17. Trudeau JD, Kelly-Smith C, Verchere CB, Elliott JF, Dutz JP, Finegood DT et al (2003) Prediction of spontaneous autoimmune diabetes in NOD mice by quantification of autoreactive T cells in peripheral blood. J Clin Invest 111(2):217-223, PMCID: 151866

18. Enee E, Martinuzzi E, Blancou P, Bach JM, Mallone R, van Endert P (2008) Equivalent specificity of peripheral blood and islet-infiltrating CD8+ T lymphocytes in spontaneously diabetic HLA-A2 transgenic NOD mice. J Immunol 180(8):5430-5438 
19. Herold KC, Brooks-Worrell B, Palmer J, Dosch HM, Peakman M, Gottlieb P et al (2009) Validity and reproducibility of measurement of islet autoreactivity by T-cell assays in subjects with early type 1 diabetes. Diabetes 58(11):2588-2595, PMCID: 2768166

20. Velthuis JH, Unger WW, Abreu JR, Duinkerken G, Franken K, Peakman $M$ et al (2010) Simultaneous detection of circulating autoreactive CD8+ T-cells specific for different islet cell-associated epitopes using combinatorial MHC multimers. Diabetes 59(7):17211730, PMCID: 2889772

21. Velthuis JH, Unger WW, van der Slik AR, Duinkerken G, Engelse M, Schaapherder AF et al (2009) Accumulation of autoreactive effector T cells and allo-specific regulatory $\mathrm{T}$ cells in the pancreas allograft of a type 1 diabetic recipient. Diabetologia 52(3):494-503

22. Brusko T, Wasserfall C, McGrail K, Schatz R, Viener HL, Schatz $\mathrm{D}$ et al (2007) No alterations in the frequency of FOXP3+ regulatory T-cells in type 1 diabetes. Diabetes 56(3):604-612

23. Tree TI, Roep BO, Peakman M (2006) A mini meta-analysis of studies on $\mathrm{CD} 4+\mathrm{CD} 25+\mathrm{T}$ cells in human type 1 diabetes: report of the Immunology of Diabetes Society T Cell Workshop. Ann NY Acad Sci 1079:9-18

24. Schneider A, Rieck M, Sanda S, Pihoker C, Greenbaum C, Buckner JH (2008) The effector T cells of diabetic subjects are resistant to regulation via $\mathrm{CD} 4+\mathrm{FOXP} 3+$ regulatory $\mathrm{T}$ cells. $\mathrm{J}$ Immunol 181(10):7350-7355, PMCID: 2597079

25. Tree TI, Lawson J, Edwards H, Skowera A, Arif S, Roep BO et al (2010) Naturally arising human CD4 T-cells that recognize islet autoantigens and secrete interleukin-10 regulate proinflammatory T-cell responses via linked suppression. Diabetes 59(6):14511460, PMCID: 2874706

26. Grinberg-Bleyer Y, Baeyens A, You S, Elhage R, Fourcade G, Gregoire $S$ et al (2010) IL-2 reverses established type 1 diabetes in NOD mice by a local effect on pancreatic regulatory T cells. J Exp Med 207(9):1871-1878

27. Tang Q, Adams JY, Penaranda C, Melli K, Piaggio E, Sgouroudis $E$ et al (2008) Central role of defective interleukin-2 production in the triggering of islet autoimmune destruction. Immunity 28 (5):687-697, PMCID: 2394854

28. Zhou X, Bailey-Bucktrout SL, Jeker LT, Penaranda C, MartinezLlordella M, Ashby M et al (2009) Instability of the transcription factor Foxp3 leads to the generation of pathogenic memory T cells in vivo. Nat Immunol 10(9):1000-1007, PMCID: 2729804

29. Voltarelli JC, Couri CE, Stracieri AB, Oliveira MC, Moraes DA, Pieroni $\mathrm{F}$ et al (2007) Autologous nonmyeloablative hematopoietic stem cell transplantation in newly diagnosed type 1 diabetes mellitus. JAMA 297(14):1568-1576

30. Sanda S, Roep BO, von Herrath M (2008) Islet antigen specific IL-10+ immune responses but not CD4+CD25+FoxP3+ cells at diagnosis predict glycemic control in type 1 diabetes. Clin Immunol 127(2):138-143

31. Kaas A, Pfleger C, Hansen L, Buschard K, Schloot NC, Roep BO et al (2010) Association of adiponectin, interleukin (IL)-1 ra, inducible protein 10, IL-6 and number of islet autoantibodies with progression patterns of type 1 diabetes the first year after diagnosis. Clin Exp Immunol 161(3):444-452

32. Roep BO, Peakman M (2010) Surrogate end points in the design of immunotherapy trials: emerging lessons from type 1 diabetes. Nat Rev Immunol 10(2):145-152

33. Tanaka S, Nishida Y, Aida K, Maruyama T, Shimada A, Suzuki M et al (2009) Enterovirus infection, CXC chemokine ligand 10 (CXCL10), and CXCR3 circuit: a mechanism of accelerated betacell failure in fulminant type 1 diabetes. Diabetes 58(10):2285-2291, PMCID: 2750208
34. Filippi CM, von Herrath MG (2008) Viral trigger for type 1 diabetes: pros and cons. Diabetes 57(11):2863-2871, PMCID: 2570378

35. Harjutsalo V, Sjoberg L, Tuomilehto J (2008) Time trends in the incidence of type 1 diabetes in Finnish children: a cohort study. Lancet 371(9626):1777-1782

36. Adams S (1926) The seasonal variation in the onset of acute diabetes. Arch Intern Med 37:861-864

37. Foulis AK, Farquharson MA, Meager A (1987) Immunoreactive alpha-interferon in insulin-secreting beta cells in type 1 diabetes mellitus. Lancet 2(8573):1423-1427

38. Dotta F, Censini S, van Halteren AG, Marselli L, Masini M, Dionisi $\mathrm{S}$ et al (2007) Coxsackie B4 virus infection of beta cells and natural killer cell insulitis in recent-onset type 1 diabetic patients. Proc Natl Acad Sci USA 104(12):5115-5120, PMCID: 1829272

39. Richardson SJ, Willcox A, Bone AJ, Foulis AK, Morgan NG (2009) The prevalence of enteroviral capsid protein vp1 immunostaining in pancreatic islets in human type 1 diabetes. Diabetologia 52(6):1143-1151

40. Smyth DJ, Cooper JD, Bailey R, Field S, Burren O, Smink LJ et al (2006) A genome-wide association study of nonsynonymous SNPs identifies a type 1 diabetes locus in the interferon-induced helicase (IFIH1) region. Nat Genet 38(6):617-619

41. Nejentsev S, Walker N, Riches D, Egholm M, Todd JA (2009) Rare variants of IFIH1, a gene implicated in antiviral responses, protect against type 1 diabetes. Science 324(5925):387-389, PMCID: 2707798

42. Stene LC, Oikarinen S, Hyöty H, Barriga KJ, Norris JM, Hutton JC, Erlich HA, Eisenbarth GSR, Rewers M (2010) Enterovirus infection and progression from islet autoimmunity to type 1 diabetes: The Diabetes and Autoimmunity Study in the Young (DAISY). Diabetes 59(12):3174-3180

43. Fauquet MAM CM, Maniloff J, Desselberger U, Ball LA (2005) Virus taxonomy: VIIIth report of the International Committee on Taxonomy of Viruses. Elsevier Academic Press, Burlington, MA

44. Roivainen M (2006) Enteroviruses: new findings on the role of enteroviruses in type 1 diabetes. Int J Biochem Cell Biol 38(56):721-725

45. Filippi CM, Estes EA, Oldham JE, von Herrath MG (2009) Immunoregulatory mechanisms triggered by viral infections protect from type 1 diabetes in mice. J Clin Invest 119(6):15151523, PMCID: 2689128

46. Shoda LK, Young DL, Ramanujan S, Whiting CC, Atkinson MA, Bluestone JA et al (2005) A comprehensive review of interventions in the NOD mouse and implications for translation. Immunity 23(2):115-126

47. Saravia-Fernandez F, Durant S, el Hasnaoui A, Dardenne M, Homo-Delarche F (1996) Environmental and experimental procedures leading to variations in the incidence of diabetes in the nonobese diabetic (NOD) mouse. Autoimmunity 24(2):113-121

48. Serreze DV, Wasserfall C, Ottendorfer EW, Stalvey M, Pierce MA, Gauntt C et al (2005) Diabetes acceleration or prevention by a coxsackievirus B4 infection: critical requirements for both interleukin-4 and gamma interferon. J Virol 79(2):1045-1052, PMCID: 538592

49. Takaki T, Marron MP, Mathews CE, Guttmann ST, Bottino R, Trucco $M$ et al (2006) HLA-A*0201-restricted T cells from humanized NOD mice recognize autoantigens of potential clinical relevance to type 1 diabetes. J Immunol 176(5):3257-3265

50. Roep BO, Atkinson M, von Herrath M (2004) Satisfaction (not) guaranteed: re-evaluating the use of animal models of type 1 diabetes. Nat Rev Immunol 4(12):989-997 